\title{
NMDA Receptor Subunit NR2b: Effects on LH Release and GnRH Gene Expression in Young and Middle-Aged Female Rats, with Modulation by Estradiol
}

\author{
Jacqueline A. Maffucci ${ }^{a}$ Deena M. Walker ${ }^{a}$ Aiko Ikegami ${ }^{b}$ Michael J. Woller ${ }^{d}$ \\ Andrea C. Gore ${ }^{a-c}$ \\ ${ }^{\mathrm{a}}$ Institute for Neuroscience, ${ }^{\mathrm{b}}$ Division of Pharmacology and Toxicology, ${ }^{\mathrm{C}}$ Institute for Cellular and Molecular \\ Biology, University of Texas, Austin, Tex., and 'Biological Sciences, University of Wisconsin-Whitewater, \\ Whitewater, Wisc., USA
}

\author{
Key Words \\ Luteinizing hormone $\cdot$ Gonadotropin-releasing hormone $\cdot$ \\ Glutamate, $N$-methyl-D-aspartate receptor $\cdot \mathrm{NR} 2 \mathrm{~b}$. \\ Reproductive aging $\cdot$ Reproductive senescence $\cdot$ Estrogen • \\ GnRH mRNA • Ifenprodil
}

\begin{abstract}
Background/Aims: The loss of reproductive capacity during aging involves changes in the neural regulation of the hypothalamic gonadotropin-releasing hormone $(\mathrm{GnRH})$ neurons controlling reproduction. This neuronal circuitry includes glutamate receptors on GnRH neurons. Previously, we reported an increase in the expression of the NR2b subunit protein of the NMDA receptor on GnRH neurons in middleaged compared to young female rats. Here, we examined the functional implications of the NR2b subunit on the onset of reproductive aging, using an NR2b-specific antagonist ifenprodil. Methods: Young (3-5 months) and middle-aged (10-13 months) female rats were ovariectomized (OVX), $17 \beta$-estradiol $\left(E_{2}\right)$ or vehicle (cholesterol) treated, and implanted with a jugular catheter. Serial blood sampling was undertaken every $10 \mathrm{~min}$ for $4 \mathrm{~h}$, with ifenprodil $(10 \mathrm{mg} / \mathrm{kg})$ or vehicle injected (i.p.) after $1 \mathrm{~h}$ of baseline sampling. The pulsatile release of pituitary LH and levels of GnRH mRNA in
\end{abstract}

\section{KARGER}

Fax +4161306 1234

E-Mail karger@karger.ch

www.karger.com (c) $2007 \mathrm{~S}$. Karger AG, Basel

$0028-3835 / 08 / 0873-0129 \$ 24.50 / 0$

Accessible online at:

www.karger.com/nen hypothalamus were quantified as indices of the reproductive axis. Results: Our results showed effects of ifenprodil on both endpoints. In OVX rats given cholesterol, neither age nor ifenprodil had any effects on LH release. In $\mathrm{E}_{2}$-treated rats, aging was associated with significant decreases in pulsatile LH release. Additionally, ifenprodil stimulated parameters of pulsatile $\mathrm{LH}$ release in both young and middle-aged animals. Ifenprodil had few effects on GnRH mRNA; the only significant effect of ifenprodil was found in the middle-aged, cholesterol group. Conclusion: Together, these findings support a role for the NR2b subunit of the NMDAR in GnRH/ $\mathrm{LH}$ regulation. Because most of these effects were exhibited on pituitary $\mathrm{LH}$ release in the absence of a concomitant change in GnRH gene expression, it is likely that NMDA receptors containing the NR2b subunit play a role in $\mathrm{GnRH}$-induced $\mathrm{LH}$ release, independent of de novo GnRH gene expression.

Copyright $\odot 2007$ S. Karger AG, Basel

\section{Introduction}

Excitatory amino acids play a major regulatory role in the neuronal release of gonadotropin-releasing hormone $(\mathrm{GnRH})$ from the hypothalamus, and subsequently lu- 
teinizing hormone (LH) from the pituitary gland, thereby affecting reproductive function. Glutamate is the most abundant excitatory amino acid in the brain, and acts via both $N$-methyl-D-asparate (NMDA) and non-NMDA (AMPA and kainate) receptors to stimulate neuronal targets, including GnRH neurons [reviewed in 1]. NMDA and AMPA receptors have been co-localized on $\mathrm{GnRH}$ neurons [2-4], and there is abundant evidence for the activation or inhibition of $\mathrm{GnRH} / \mathrm{LH}$ release in response to NMDA and non-NMDAR agonists and antagonists, respectively, both in vitro and in vivo [5-14]. This includes their involvement in the control of the pulsatile pattern of LH release [5, 9-11], which is necessary for normal physiologic function [15-17]. Thus, glutamate receptors are part of the neural circuitry that regulates reproductive neuroendocrine function.

During the transition to middle age, female rats exhibit a number of changes in their reproductive capacity, including a shift from a regular (4- to 5-day) estrous cycle to an irregular ( $>5$-day) cycle and finally acyclicity $[18$, 19]. During this period, a decline in LH levels [20] and changes in GnRH/LH pulsatile release including decreases in LH amplitude and interpulse interval [21-23] can be detected. Additionally, the effect of age on $\mathrm{GnRH}$ gene expression is debated, as studies show increases, decreases and no change dependent upon the methodology used and hypothalamic nuclei assayed [reviewed in 24]. $\mathrm{GnRH}$ protein expression during this transition period also shows very little to no significant changes [2, 25-27]. This suggests that the major change to the reproductive axis during this time is not to the expression of $\mathrm{GnRH}$ neurons, but rather its regulation by the neural circuitry influencing its actions. Numerous neurotransmitters and neurotrophic factors act on the GnRH neuron, both directly and indirectly. These are also undergoing age-related changes, and thus affect functional alterations in the hypothalamic control of reproduction.

There is evidence that hypothalamic glutamate plays a role in these age-associated changes, both through changes in glutamate release [28] and through altered responsiveness of NMDARs [12] due to changes in glutamate's interactions with NMDARs. The NMDAR-stimulated release of mean LH seen in young rats is attenuated in middle-aged females [14] and aged (21-23 months) males [12]. To the authors' knowledge, effects of NMDAR inhibition on $\mathrm{LH}$ release have not been reported in an aging rat model. However, administration of the NMDAR antagonist AP-5 to adult gonadectomized male $[5,10]$ or female [11] rats results in a decline of LH pulse amplitude and mean levels in both males and females, as well as a decline of LH pulse frequency and interpulse interval in females. Thus, we suggest that age-associated changes in the expression or function of hypothalamic NMDARs contributes to alterations in $\mathrm{GnRH} / \mathrm{LH}$ pulsatile release.

Effects of glutamate agonists and antagonists on GnRH neurons are also modified by the steroid hormone environment. There is substantial co-expression of the NMDAR with estrogen receptors in the hypothalamus and preoptic area, suggesting that glutamate and estrogens may act on the same target cells to influence $\mathrm{GnRH}$ neurons [29, 30]. In most studies, effects of NMDAR activation on $\mathrm{GnRH}$ neurons are enhanced in the presence of estradiol $\left(\mathrm{E}_{2}\right)[31,32]$.

In the present study, we focused on the role of one NMDAR subunit, NR2b, and its age-related regulation of pulsatile LH release in female rats. The choice of the NR2b subunit was based upon previous evidence showing that this subunit specifically undergoes developmental and age-associated increases in its expression on GnRH neurons $[2,33]$, and the NR2b gene is associated with a quantitative trait locus thought to be involved in the regulation of puberty in mice [34]. Along with their expression on GnRH cells, NMDARs are also abundantly expressed on non-GnRH neurons in the hypothalamus, including regions that regulate $\mathrm{GnRH}$ release, and these also undergo age-related changes $[3,30,31]$. Thus, effects of NMDAR activation on GnRH release involve both direct and indirect actions. Here, we used an NR2bselective antagonist, ifenprodil, to assess the role of the NR2b subunit on GnRH activity in the context of aging (young vs. middle-aged) and hormone environment (ovariectomy plus vehicle or $17 \beta-\mathrm{E}_{2}$ ).

\section{Methods}

\section{Animals}

A total of 76 female Sprague-Dawley rats were used in this study, with 38 young (3-5 months) and 38 middle-aged (10-12 months). All were purchased from The University of Texas at Austin Animal Resource Center rat colony (Austin, Tex., USA), which contains animals received and bred from Harlan Sprague-Dawley, Inc. (Indianapolis, Ind., USA). Animals were group housed (2-3/cage) in a temperature-controlled room $\left(21-22^{\circ} \mathrm{C}\right)$ with a $12 \mathrm{~h}$ light, $12 \mathrm{~h}$ dark reverse cycle (lights on at 01:00 h). Food (standard rat chow) and water were provided ad libitum. All animal protocols were conducted in accordance with the Guide for the Care and Use of Laboratory Animals [35] following protocols approved by The University of Texas at Austin IACUC.

\section{Surgical Procedures}

The cycling status of all young and middle-aged animals was first determined through examination of daily vaginal cytology, 
observed for a minimum of 10 days. Rats were characterized as regularly cycling (4- to 5-day estrous cycles), irregularly cycling (6+ day estrous cycles) or acyclic (persistent estrus). Cycling animals were ovariectomized (OVX) at 10:00 h on diestrus (for young, regularly cycling and middle-aged, irregularly cycling animals). Acyclic rats were OVX on persistent estrus (middle-aged, acyclic animals). Surgeries were performed under isoflurane gas anesthesia and rats were treated postoperatively with $5 \mathrm{mg} / \mathrm{kg}$ Rimadyl. 4-6 weeks later, animals were subcutaneously implanted at 10:00 h with a Silastic capsule (capsule dimensions: inner diameter $1.96 \mathrm{~mm}$; outer diameter $3.18 \mathrm{~mm}$ ) containing either $5 \%$ $17 \beta$-estradiol $/ 95 \%$ cholesterol $\left(\mathrm{E}_{2}\right)$ or $100 \%$ cholesterol (Chol; Sigma-Aldrich, St. Louis, Mo., USA) as vehicle, under isoflurane anesthesia (day 0). Young animals received an implant $1.0 \mathrm{~cm}$ in length; middle-aged animals received an implant $1.5 \mathrm{~cm}$ in length. Different lengths were used to account for size differences associated with age differences [36]. Following surgery, animals were housed individually. Two days following hormone replacement (day 2), animals were implanted with a jugular catheter [modified from 37]. Rats were anesthetized with ketamine $(90 \mathrm{mg} / \mathrm{kg}$, i.p.) and xylazine $(10 \mathrm{mg} / \mathrm{kg}$, i.p.). A Silastic catheter $(0.51 \mathrm{~mm}$ inner diameter, $0.94 \mathrm{~mm}$ outer diameter) was inserted into the right jugular vein and advanced into the right atrium. A cannula (Plastics One, Roanoke, Va., USA), located at the distal end of the catheter, was subcutaneously routed around the neck and out through an incision on the top of the head. Here, it was affixed to the skull with stainless steel screws and dental acrylic cement. Catheters were flushed daily and patency verified using $0.1 \mathrm{ml}$ of $30 \mathrm{U} / \mathrm{ml}$ heparinized saline, $62 \mathrm{mg} / \mathrm{ml}$ Timentin. In cases where the jugular catheter did not remain patent through serial blood sampling, animals were given a new catheter in the left jugular vein (day 4) and serial blood draws were resumed on day 6 . There was no effect of this process on any results.

\section{Serial Blood Sampling}

On day 4, from 10:00 to 14:00 h, animals were placed in aquaria divided into two chambers with no visual or tactile contact. Catheters were attached to St. Gobain tubing (inner diameter $0.508 \mathrm{~mm}$; outer diameter $1.524 \mathrm{~mm}$; VWR \#63018-044), attached to a 22-gauge needle with a 3 -cc syringe filled with $5 \mathrm{U} / \mathrm{ml}$ heparinized saline. Syringes were suspended from the top of the aquaria, allowing the animals to move freely during serial blood sampling. $0.2 \mathrm{cc}$ of blood was collected into heparinized microcentrifuge tubes $(1,000 \mathrm{U} / \mathrm{ml})$ every $10 \mathrm{~min}$ for $4 \mathrm{~h}$. Following each collection, bloods were centrifuged at $600 \mathrm{~g}$ for $5 \mathrm{~min}$. Serum was collected and stored on ice. The remaining red blood cells were resuspended in an equal volume of $5 \mathrm{U} / \mathrm{ml}$ of heparinized saline and reinfused into the animal in order to maintain hematocrit levels.

\section{Drug Administration}

Animals were administered either vehicle ( $0.1 \%$ tartaric acid) or ifenprodil tartrate $\left(10 \mathrm{mg} / \mathrm{kg}\right.$ b.w.; $\mathrm{ddH}_{2} \mathrm{O}$; Sigma-Aldrich) intraperitoneally (i.p.) following $1 \mathrm{~h}$ of serial blood sampling. This dose and route were chosen based on preliminary and published in vivo experiments, showing central nervous system effects in both mice and rats [38, 39]. Specifically, Narita et al. [38] used a $10-\mathrm{mg} / \mathrm{kg}$ i.p. dose in mice to demonstrate the involvement of the NR2b subunit in ethanol withdrawal, and further showed a change in the NR2b subunit limbic forebrain population follow- ing treatment. Rodrigues et al. [39] used varying concentrations of ifenprodil $(1,3$, and $10 \mathrm{mg} / \mathrm{kg})$ to demonstrate a dose-dependent inhibition of fear acquisition in rats, with $10 \mathrm{mg} / \mathrm{kg}$ showing the strongest effects. In a pilot study in our laboratory we examined the effects of both 1- and 10-mg/ $\mathrm{kg}$ dose on LH levels in female rats, and found the $10-\mathrm{mg} / \mathrm{kg}$ dose to be most effective. Higher doses were not examined due to concerns about neurotoxicity.

\section{Collection of Hypothalamic Tissue and Trunk Blood}

Following serial blood samples (4 h), animals were humanely euthanized by decapitation. Trunk bloods were collected, allowed to clot, and centrifuged at $6,000 \mathrm{~g}$. Serum was stored at $-80^{\circ} \mathrm{C}$ for later $\mathrm{LH}$ and estrogen radioimmunoassay. Brains were removed and the preoptic area-anterior hypothalamus (POA-AH) was dissected, as described previously [40]. Briefly, dissections were done using a cold, stainless steel brain matrix, flash-frozen on dry ice, and stored at $-80^{\circ} \mathrm{C}$.

\section{RNA Extraction for Real-Time PCR}

RNA was extracted from frozen POA-AH tissues using a wellestablished in-house double detergent lysis buffer system, adapted from Jakubowski and Roberts [40]. Briefly, tissues were homogenized via extrusion through a 22 -gauge needle, treated with proteinase $\mathrm{K}$, and RNA was extracted in phenol chloroform and precipitated in ethanol. Nuclear and cytoplasmic portions were separated using a two-buffer system. The cytoplasmic RNA of each animal was treated with DNase Free kit (Ambion, Austin, Tex., USA) according to manufacturer's specification. RNA integrity was confirmed using a bioanalyzer (Agilent 2100) and the concentration determined using Nanodrop ND-1000. RNA was then stored at $-80^{\circ} \mathrm{C}$ until use in real-time PCR.

\section{Real-Time PCR}

GnRH gene expression was determined in the POA-AH and normalized to a housekeeping gene, cyclophilin [41, 42]. A reverse transcriptase reaction was carried out using $2 \mu \mathrm{g}$ of cytoplasmic RNA with Superscript II Reverse Transcriptase (Invitrogen, Carlsbad, Calif., USA), according to the manufacturer's instructions. The product was stored at $-20^{\circ} \mathrm{C}$ until use, at which time cDNA was diluted 1:5 before PCR reactions were performed.

Real-time PCR was performed using the Stratagene Brilliant ${ }^{\circledR}$ qPCR master mix and were run on a Stratagene MX3000 (Stratagene, La Jolla, Calif., USA) using the following reaction parameters: 1 cycle at $\left(95^{\circ} \mathrm{C}\right.$ for 10 min followed by 45 cycles at $95^{\circ} \mathrm{C}$ for $30 \mathrm{~s}, 55^{\circ} \mathrm{C}$ for $1 \mathrm{~min}$, and $72^{\circ} \mathrm{C}$ for $30 \mathrm{~s}$. All reactions were run using primer and probe sequences developed and tested in house (GnRH) or as previously published (cyclophilin [41]) (IDT, Coralville IA Primers; Eurogentec) at concentrations listed in table 1. A validation experiment was performed for the GnRH and cyclophilin assays to ensure that the reaction efficiencies were comparable. Each product was run on a $3 \%$ agarose gel to confirm amplicon length and specificity. A no reverse transcriptase (no RT) control was run for each sample to determine if genomic contamination was present. Any samples containing significant contamination were discarded from analysis $(\Delta \mathrm{Ct} \geq 10)$. A positive control was run on each plate to determine interassay variability.

Relative expression of GnRH mRNA levels, normalized to cyclophilin mRNA levels and calibrated with a positive control, was determined using the $\Delta \Delta$ Ct method [43]. Samples were run in 
Table 1. Cyclophilin and GnRH primer and probe sequences for real-time PCR reaction

\begin{tabular}{|c|c|c|c|c|}
\hline Gene & Forward primer $\left(5^{\prime}-3^{\prime}\right)$ & Reverse primer $\left(3^{\prime}-5^{\prime}\right)$ & Probe (Taqman only) & $\begin{array}{l}\text { [Primer] }(\mathrm{nm}) \\
\text { [Probe] }(\mathrm{nM})\end{array}$ \\
\hline Rat cyclophilin ${ }^{1}$ & $\begin{array}{l}5^{\prime} \text {-TGT GCC AGG GTG } \\
\text { GTG ACT T-3' }\end{array}$ & $\begin{array}{l}5^{\prime}-\mathrm{TCA} \text { AAT TTC TCT CCG } \\
\text { TAG ATG GAC TT-3' }\end{array}$ & $\begin{array}{l}5^{\prime} \text {-CCA CCA GTG CCA TTA } \\
\text { TGG CGT GT-3' }\end{array}$ & $\begin{array}{l}\text { F: } 300 \text { R: } 300 \\
\text { Probe: } 150\end{array}$ \\
\hline Rat $\mathrm{GnRH}^{2}$ & $\begin{array}{l}5^{\prime} \text {-CCC TTT GGC TTT } \\
\text { CAC ATC CA-3' }\end{array}$ & $\begin{array}{l}5^{\prime} \text {-AAC AGC GGC CAT } \\
\text { CAG TTT G-3' }\end{array}$ & $\begin{array}{l}5^{\prime} \text {-ACA GAA TGG AAA } \\
\text { CGA TCC-3' }\end{array}$ & $\begin{array}{l}\text { F: } 900 \text { R: } 900 \\
\text { Probe: } 300\end{array}$ \\
\hline
\end{tabular}

triplicate and analyzed in duplicate to account for pipetting errors. Interassay variability was $9.0 \%$.

\section{Radioimmunoassay (RIA)}

$L H$. LH in serum samples was determined in single samples using double antibody RIA. This RIA was performed using the rat LH RP-3 standard, iodinate and antibody from the National Hormone and Pituitary Program of the NIDDK (kindly provided by Dr. A.F. Parlow). Three assays were performed. The assay sensitivity was $0.03 \mathrm{ng} /$ tube at $85 \%$ binding. The intraassay variability ranged from 3.6 to $12.3 \%$. Interassay variability was $2.95 \%$.

Estradiol. $\mathrm{E}_{2}$ levels were determined in serum samples from trunk bloods when there was residual serum from the LH assay. The DSL ultrasensitive estradiol kit (DSL-4800, Diagnostic Systems Laboratories, Inc., Webster, Tex., USA) was used according to the included instructions. Samples were run in duplicate in a single assay. The intraassay variability was $2.8 \%$.

\section{Statistical Analysis}

LH Pulse Analysis. A computer-based pulse detection method, Cluster, was used to analyze pulsatile release of LH [44]. This is available in the Pulse_XP software suite provided by Michael L. Johnston (University of Virginia, Va., USA). This algorithm identifies significant increases and decreases within a data set in relation to measurement error inclusive to experimental data. A moving nadir (referred to as a test nadir and defined as a cluster of points) of two points for test nadir were compared to two experimental points using pooled t-test to determine significant rises within the data set. The entire data set is examined for increases in significance through shifting of test nadir and experimental points by one sample. This continues through the entire series, and upon completion, the process moves in reverse to determine significant falls in the data. A peak is defined as a significant increase followed by a significant decrease, and thus a peak must be surrounded by nadirs on each side.

In this analysis, we used parameters suggested by the program developers. In brief, this includes 2 points used to define peaks and nadirs, a t statistic of 2.75 for significant increases and 1.5 for significant decreases, and 2 degrees of freedom for sample mean [44]. Analyses include mean LH (average LH value for the entire experimental period from the second to the penultimate sample (see below)), pulse frequency (number of peaks) and amplitude (height of peaks), pulse width (in minutes) and area (defined as the product of the mean peak subtracted from the average of the pre- and post-peak nadirs multiplied by the peak width), interpeak intervals (between peak regions) and interpeak concentrations [44]. Significant changes in these variables were determined using one-way and two-way analysis of variance (ANOVA) and the Kruskal-Wallis non-parametric test, when normality assumptions were violated. The effects of age and drug, as well as their interactions, were tested. Post-hoc analyses were performed when a significant main effect was detected. An effect was considered significant at $\mathrm{p}<0.05$.

Raw data were rescaled to fit all points within the same range. Any animals with one or more data point reaching minimal or maximal detectability of the LH RIA assay were excluded based on recommendations from a biostatistician, Dr. W.Y. Wendy Lou. Thus, the numbers of animals shown in the Results section differ from the initial numbers of animals assigned to this study. The final n's used for analysis are presented in the figure legends. The initial data point for each data set was dropped to limit effects of stress on LH levels during the initiation of serial blood sampling, and the final data point was excluded from analysis because it was collected at the time of terminal decapitation. Finally, no differences were observed in irregularly cycling middle-aged animals $(n=25)$ when compared to those in persistent estrus $(n=8)$, so these groups were combined.

GnRH mRNA Analysis. GnRH mRNA levels were normalized to the housekeeping gene cyclophilin in each animal. All results are expressed as the mean \pm SEM. ANOVA was performed by the StatView 5.0 program for Macintosh computer to ascertain differences between groups. Results were considered significant at $\mathrm{p}<0.05$.

Fig. 1. Individual profiles of pulsatile LH release, measured in serum samples collected every $10 \mathrm{~min}$ in representative young $(\mathbf{a}, \mathbf{b})$ and middle-aged (c, d) OVX, cholesterol replaced female rats. Please note that the $y$-axis scales vary among treatment groups to better demonstrate individual pulses. Animals were injected with vehicle or ifenprodil $(10 \mathrm{mg} / \mathrm{kg}) 1 \mathrm{~h}$ after blood sampling began. Arrows indicate the time point immediately preceding the injection. Asterisks indicate significant pulses as indicated by the Cluster pulse detection software. $\mathrm{Chol}=$ Cholesterol. 


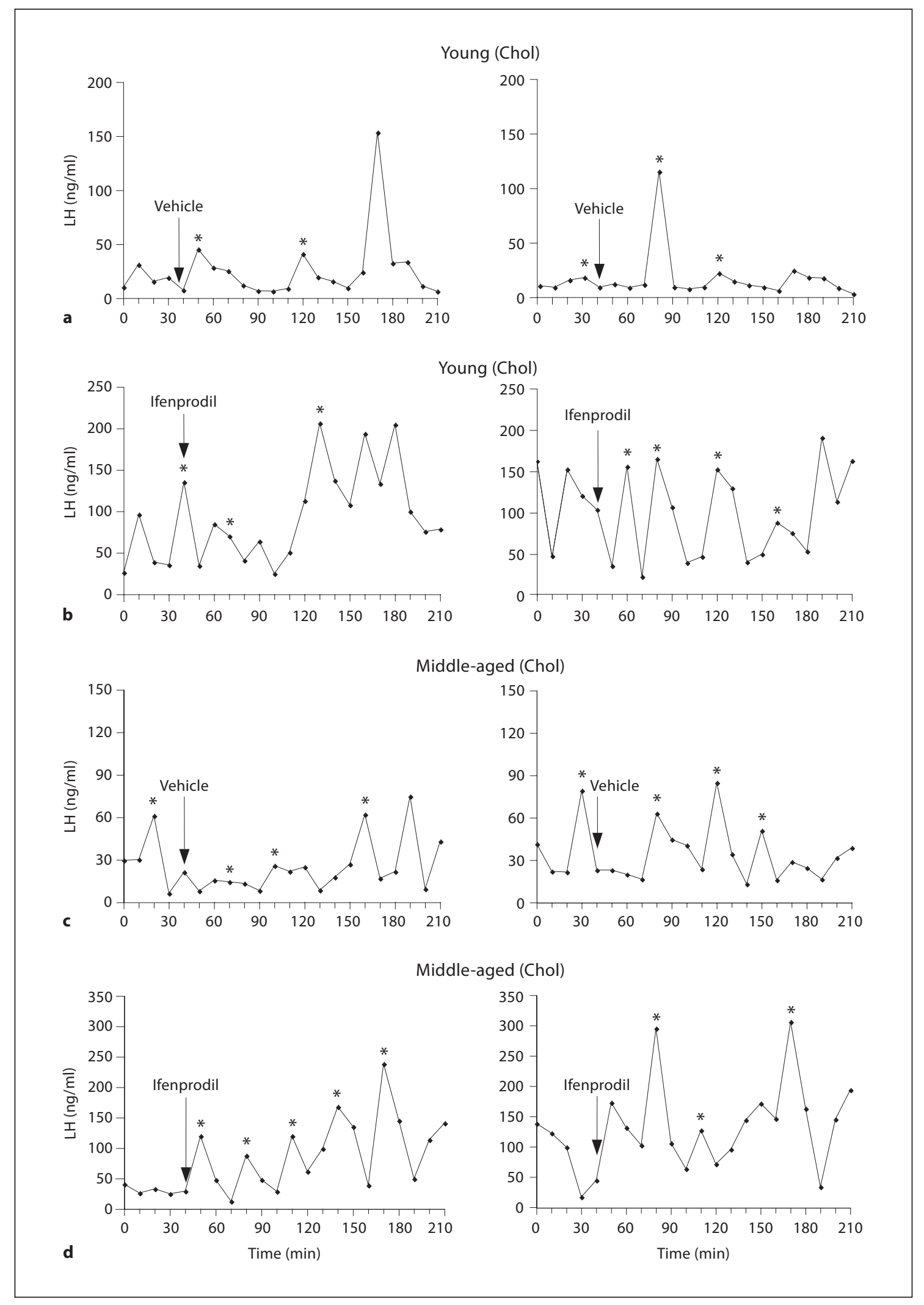




\section{Results}

\section{Effects of Ifenprodil on LH Release in Young and} Middle-Aged Female Rats

The LH profiles for 2 representative animals from each group of cholesterol- and $17 \beta-\mathrm{E}_{2}$-treated animals are shown in figures 1 and 2 respectively. Rats had detectable pulses of $\mathrm{LH}$ in all treatment groups. As expected, serum LH levels were high in OVX, cholesterol-treated young and middle-aged rats (fig. 1) and were low in OVX, $E_{2}$-treated rats due to negative feedback of $E_{2}$ on $\mathrm{GnRH}$ and LH (fig. 2).

Cholesterol-Treated Animals. The selective NR2b antagonist, ifenprodil, had no effect on the parameters of total and pulsatile $\mathrm{LH}$ release, including area under the LH curve (fig. 3a), area under the peak (fig. 3b), mean LH release (fig. 3c), or LH peak amplitude (fig. 3d). In addition, in OVX, cholesterol-treated rats, none of these parameters differed between young and middle-aged rats. In this group, as well as in the $\mathrm{E}_{2}$ animals described below, the following parameters were not significantly affected by ifenprodil: pulse frequency, pulse width, interpeak intervals, and interpeak concentrations (data not shown).

$17 \beta-E_{2}$-Treated Animals. In contrast to the cholesterol group, there was both an age and drug effect observed for serum LH levels. Post-hoc analyses showed that middleaged $\mathrm{E}_{2}$-treated animals had significantly lower levels of $\mathrm{LH}$ as compared to young animals in the measurements of area under the LH curve (fig. $4 \mathrm{a} ; \mathrm{p}<0.003$ ), area under the peak (fig. $4 b, p=0.0346$ ), mean LH (fig. $4 c ; p=0.001$ ), and peak amplitude (fig. $4 \mathrm{~d} ; \mathrm{p}=0.0039$ ). Additionally, administration of ifenprodil caused increases in three of these parameters: area under the LH curve (fig. $4 \mathrm{a}$; $\mathrm{p}=$ 0.0151); mean LH (fig. 4c; $p=0.014$ ) and peak amplitude (fig. $4 \mathrm{~d} ; \mathrm{p}=0.0134$ ), but not area under the peak.

\section{Effects of Ifenprodil on GnRH mRNA Expression in} the POA-AH of Young and Middle-Aged Female Rats

No effects of either age or hormone on GnRH mRNA levels were observed, as these were similar in cholesteroland $\mathrm{E}_{2}$-treated rats, as well as young and middle-aged rats (fig. 5). The only significant difference detected was for drug (ifenprodil vs. vehicle) in the middle-aged, cholesterol-treated rats. In this group, GnRH mRNA levels were modestly but significantly lower in ifenprodil-treated rats $(\mathrm{p}<0.05)$ as compared to their vehicle-treated counterparts.
$17 \beta-E_{2}$ Levels in Young and Middle-Aged,

\section{OVX Female Rats}

The average $\mathrm{E}_{2}$ levels for OVX young and middle-aged, cholesterol-treated rats were $1.01 \pm 0.14$ and $0.76 \pm 0.26$ $\mathrm{pg} / \mathrm{ml}$, respectively. The average $\mathrm{E}_{2}$ levels for OVX, $\mathrm{E}_{2^{-}}$ treated young and middle-aged rats were $332 \pm 102$ and $314 \pm 51 \mathrm{pg} / \mathrm{ml}$, respectively. Although levels of $E_{2}$ were higher than anticipated and were often supraphysiological, each treatment group included animals with levels ranging from the physiological to the supraphysiological range, and there were no differences in results from animals across this range of $\mathrm{E}_{2}$ levels. The results also showed comparable replacement levels of $\mathrm{E}_{2}$ in the young and middleaged rats.

\section{Discussion}

The present results add to the mounting evidence for the regulation of the neuroendocrine hypothalamus by glutamate, showing for the first time a functional role for the NR2b subunit of the NMDAR. Here, we used the NR2b-selective antagonist ifenprodil and measured its effects on serum LH levels as a proxy for GnRH release, which cannot be measured in the general circulation. However, actions of NMDAR agonists/antagonists on pituitary LH release are mediated exclusively through hypothalamic GnRH neurons [1, 7, 12-14, 45, 46], and therefore, any effects of ifenprodil on LH release likely represent its effects on hypothalamic $\mathrm{GnRH}$ release. Our current study shows that treatment with ifenprodil results in significantly higher levels of pulsatile LH than vehicle controls. Both young and middle-aged rats were responsive to ifenprodil, and this effect was limited to rats given $\mathrm{E}_{2}$ (but not cholesterol) treatment, suggesting that the steroid environment modifies effects of NMDARacting drugs on GnRH output. The implications of these findings, as discussed in greater detail below, are that the subunit composition of the NMDAR plays a role in its function in the reproductive neuroendocrine system.

Fig. 2. Individual profiles of pulsatile LH release, measured in serum samples collected every $10 \mathrm{~min}$ in representative young $(\mathbf{a}, \mathbf{b})$ and middle-aged $(\mathbf{c}, \mathbf{d}) \mathrm{OVX}, 17 \beta-\mathrm{E}_{2}$ replaced female rats. Please note that the $y$-axis scales vary among treatment groups to better demonstrate individual pulses. Animals were injected with vehicle or ifenprodil $(10 \mathrm{mg} / \mathrm{kg}) 1 \mathrm{~h}$ after blood sampling began. Arrows indicate the time point immediately preceding the injection. Asterisks indicate significant pulses as indicated by the Cluster pulse detection software. $\mathrm{E}_{2}=17 \beta$-Estradiol. 


\section{Young $\left(E_{2}\right)$}
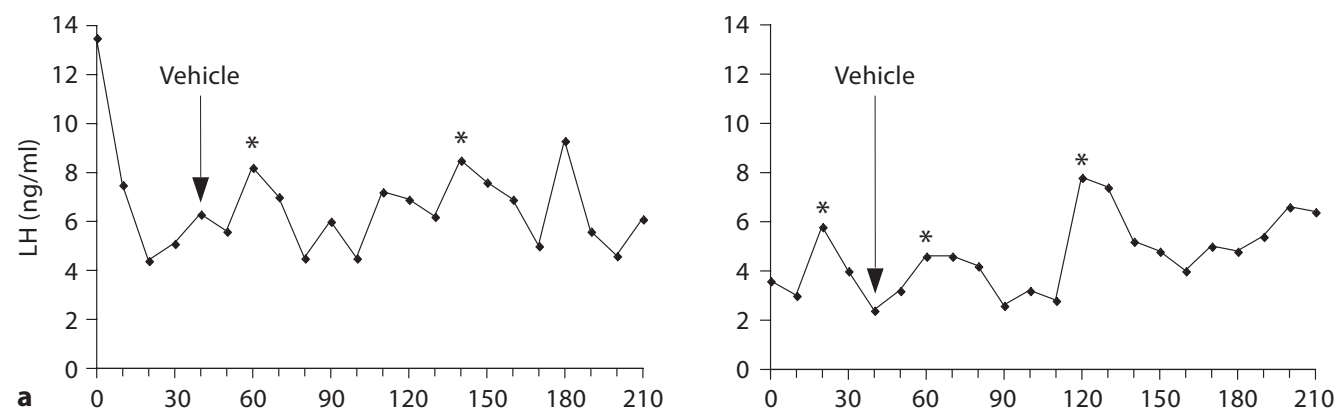

Young $\left(E_{2}\right)$
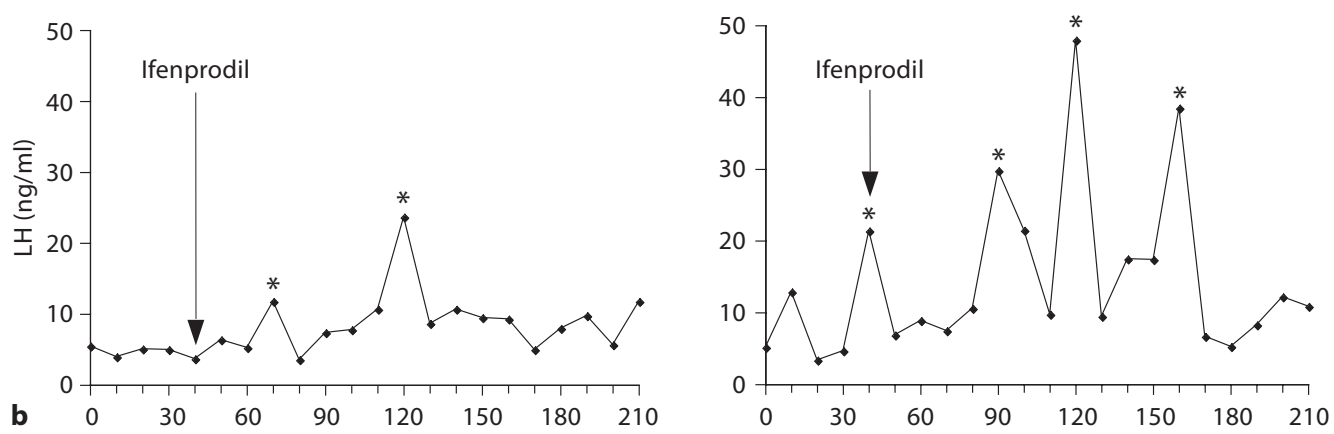

Middle-aged $\left(E_{2}\right)$
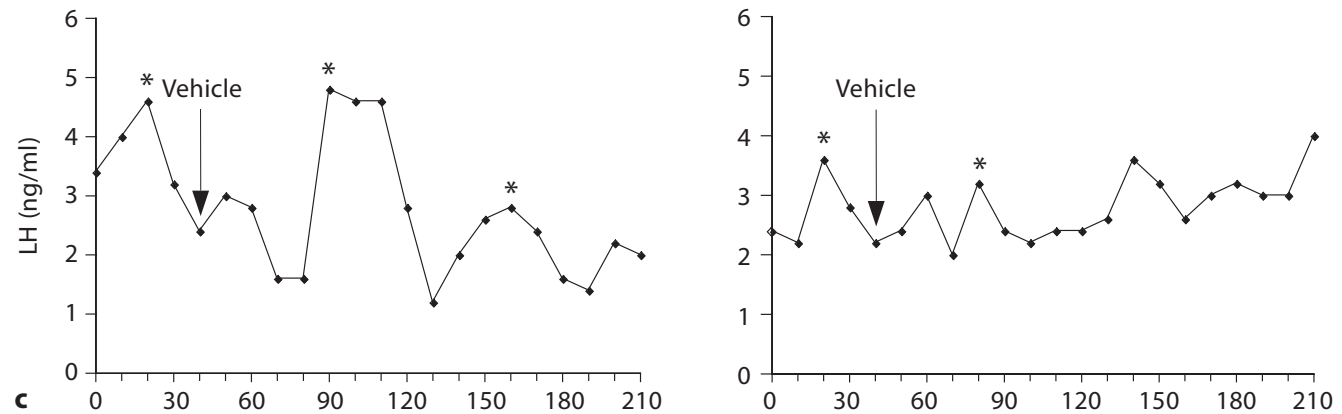

Middle-aged $\left(E_{2}\right)$
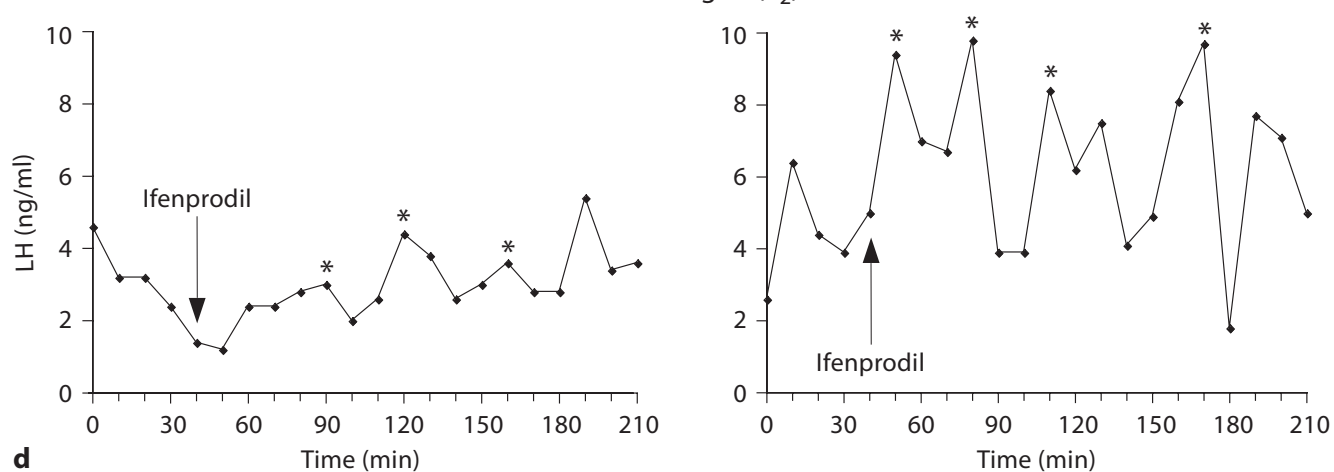
Fig. 3. Parameters of pulsatile LH release were determined in young and middleaged female rats that were OVX and treated with cholesterol. Group data (mean \pm SEM) are shown for area under the $\mathrm{LH}$ concentration curve (a), area under the LH peak (b), mean LH (c), and LH peak amplitude (d). There were neither any significant effects of age (young vs. middle-aged) nor drug treatment (ifenprodil vs. vehicle) on any parameters of $\mathrm{LH}$ release. $\mathrm{n}=3$, 7,4 , and 8 for young vehicle, young ifenprodil, middle-aged vehicle, middle-aged ifenprodil, respectively. $\mathrm{Chol}=$ Cholesterol; $\mathrm{VEH}=$ vehicle; IFEN = ifenprodil; $\mathrm{AUC}=$ area under the curve; $\mathrm{AUP}=$ area under the peak.

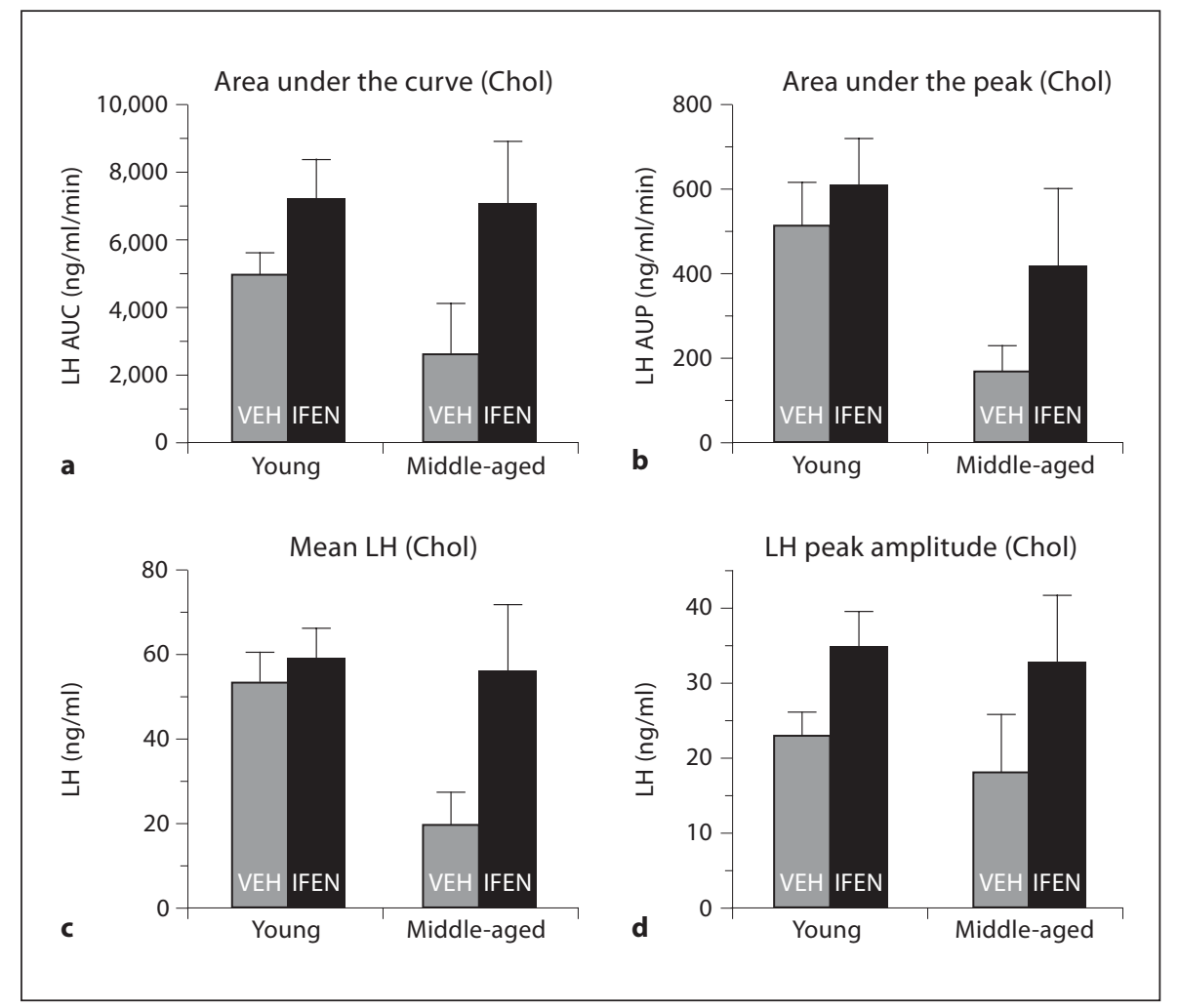

NMDAR Regulation of GnRH Neurons:

Role of the NR2b Subunit

Previous studies have shown that at the dose used in the current study, ifenprodil is a selective antagonist for NMDARs containing the NR2b subunit $[47,48]$, crosses the blood-brain barrier $[49,50]$, and exerts actions in the central nervous system for at least $2 \mathrm{~h}$ [50] and up to $12 \mathrm{~h}$ post-application [38]. Here, ifenprodil injection enhanced pulsatile $\mathrm{LH}$ release in young and middle-aged OVX, $\mathrm{E}_{2}-$ treated rats. This finding suggests that the presence of the NR2b subunit in NMDARs affecting GnRH neurons decreases their responsiveness to endogenous glutamate. This result may be explained by the stoichiometry and properties of the NMDAR, which is a heteromeric complex composed of an NR1 subunit, necessary for channel function, co-assembled with one or more types of NR2 $(a-d)$ or NR3 $(a, b)$ subunits. The subunit composition of the NMDAR alters its properties, influencing channel kinetics, intracellular responses, and ligand affinities [51]. NR1, NR2a, and NR2b are the most abundant subunits expressed in the hypothalamus [52-54] and all are co-expressed by $\mathrm{GnRH}$ cell bodies and nerve terminals $[2,26$, $32,55]$. Of these, only the NR2b subunit shows age-associated changes, increasing its co-expression on $\mathrm{GnRH}$ neurons in the POA-AH, an area rich in GnRH perikarya, of middle-aged females as compared to their young counterparts [2]. A previous report indicated that the presence of the NR2b subunit in the NMDAR complex is associated with a decreased probability of channel opening, increased deactivation time, and slower recovery from desensitization when compared to NR2a [56]. Thus, it is our belief that the previously demonstrated age-related increase in NR2b co-expression on the GnRH neurons of the POA-AH, and hence an increase in the ratio of NR2b- to NR2a-containing receptors, causes delayed and decreased channel opening, resulting in a decline in the efficiency by which the NMDAR stimulates GnRH release. Our current results showing an enhancement of pulsatile LH release by ifenprodil, which selectively blocks receptors containing NR2b but would enable activity of NMDARs that do not contain NR2b, are consistent with this hypothesis.

In the present study, we observed a significant increase in area under the LH curve, mean LH, and LH pulse amplitude following ifenprodil treatment in both age groups of $\mathrm{E}_{2}$-treated OVX rats. We interpret this to mean that blockade of NMDARs containing the NR2b subunit allows other (non-NR2b-containing) NMDARs to mediate 
Fig. 4. Parameters of pulsatile LH release were determined in young and middleaged female rats that were OVX and treated with $\mathrm{E}_{2}$. There was a significant decline with age in area under the LH concentration curve (a), area under the peak (b), mean LH (c) and LH peak amplitude (d). Ifenprodil administration resulted in a significant increase in area under the curve, mean $\mathrm{LH}$, and $\mathrm{LH}$ peak amplitude in both young and middle-aged OVX, $\mathrm{E}_{2}$ treated rats. All data shown are mean \pm SEM. $\mathrm{n}=10,4,5$, and 5 for young vehicle, young ifenprodil, middle-aged vehicle, and middle-aged ifenprodil, respectively. ${ }^{*} \mathrm{p}<0.05$ vs. comparable drug or age group; ${ }^{*} \mathrm{p}<0.01$ vs. comparable drug or age group. $\mathrm{E}_{2}=$ Estradiol; $\mathrm{VEH}=$ vehicle; IFEN = ifenprodil; AUC = area under the curve; AUP = area under the peak.

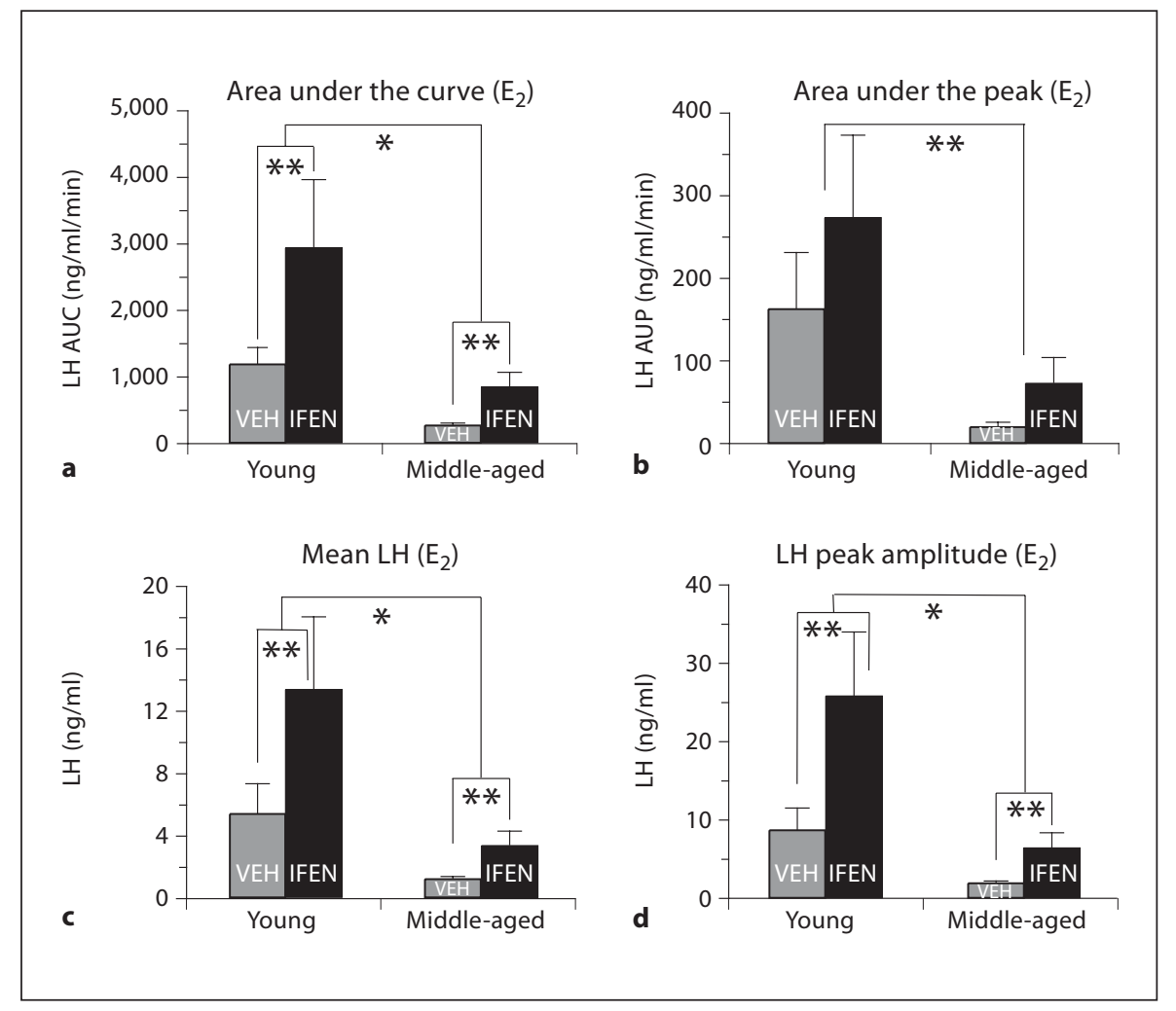

effects of glutamate, resulting in either an increase in the number of GnRH neurons firing or the amount of peptide being released during individual neuronal firing. This is further supported by the observed increase in mean LH and area under the LH curve. Furthermore, the lack of significant change of LH area under the peak suggests that ifenprodil is acting to increase baseline levels of $\mathrm{LH}$, rather than simply increase the concentration released during each pulse.

We were surprised that OVX, $E_{2}$-treated rats of both age groups responded in a similar way to ifenprodil. However, both age groups have NR2b-containing NMDARs, albeit at differing levels [2, 26, 31], and both received a treatment that altered the NMDAR population. Ifenprodil binds only to NMDARs containing the NR2b subunit, and its effectiveness at inhibiting these channels is determined by the receptor stoichiometry, specifically, the number of NR2b subunits encompassed within the channel [57]. Moreover, as discussed below, not only does ifenprodil act upon GnRH neurons, but it also exerts effects on afferents to this system that may also possess NMDARs with NR2b subunits. Thus, the heterogeneous nature of this receptor, as well as the multiple mechanisms by which it may exert influence on the reproductive axis (both directly and indirectly), suggests that ifenprodil may exert broad effects on this hypothalamic neural circuitry regulating $\mathrm{GnRH}$. This may underlie why both young and middle-aged rats are responsive to ifenprodil, as it may be through different populations of NMDARs, and warrants further investigations to tease apart these mechanisms.

It seems counterintuitive that blockade of receptors for an excitatory amino acid such as glutamate may result in an up-regulation of pulsatile LH release. We feel that the most reasonable explanation is that the effects of ifenprodil are occurring not only on GnRH neurons themselves, but also on neurons that make direct and indirect inputs to GnRH cells. For example, GABA-containing neurons, the principal inhibitory neurotransmitter in the brain and the counterpart to glutamate's role as the principal excitatory neurotransmitter, inhibit GnRH release [58, 59]. If this GABAergic inhibition is stimulated by glutamate, the removal of glutamatergic input by ifenprodil to these GABAergic neurons would disinhibit GnRH neurons, thereby facilitating $\mathrm{GnRH}$ release. It is even possible that the same neurons co-express glutamate and GABA and that the balance of their outputs affect $\mathrm{GnRH}$ release, as postulated by Ottem et al. [60]. Moreover, there are age 


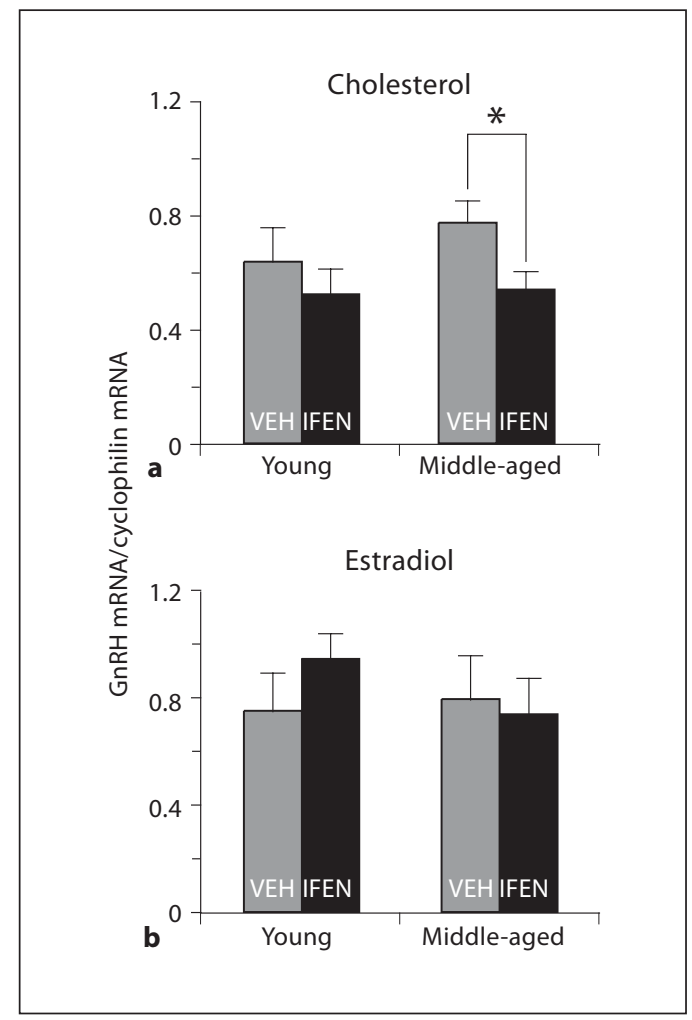

Fig. 5. GnRH mRNA levels in the preoptic area-anterior hypothalamus, normalized to cyclophilin mRNA, were quantified by real-time PCR. Data are shown for the OVX cholesterol- (a) and $\mathrm{E}_{2}$-treated (b) rats. No overall effect of age or drug treatment was detected, although a significant interaction of age $\times$ treatment was detected, which was attributable to the OVX, cholesteroltreated middle-aged group, in which ifenprodil caused a small but significant decrease in GnRH mRNA levels. ${ }^{*} \mathrm{p}<0.05 . \mathrm{VEH}=$ Vehicle; IFEN = ifenprodil. a Cholesterol rats, $n=6,6,8$ and 8 for young vehicle, young ifenprodil, middle-aged vehicle, and middle-aged ifenprodil, respectively. $\mathbf{b} \mathrm{E}_{2}$ rats, $\mathrm{n}=8,5,6$ and 8 for the same respective groups.

alterations in hypothalamic-preoptic GABA release and biosynthesis in rats [61]. Thus, the balance of glutamate and GABA regulation of GnRH neurons, directly and/or indirectly, may play important roles in neuroendocrine regulation.

\section{$E_{2}$-NMDAR Interactions}

Ifenprodil significantly enhanced pulsatile $\mathrm{LH}$ release only in OVX rats treated with $\mathrm{E}_{2}$, but not cholesteroltreated OVX rats. These findings are consistent with previous evidence for an enhanced sensitivity of the GnRH neurosecretory system to NMDAR agonists or antago- nists in the presence of estrogens $[13,31,62]$. For example, pulsatile LH release in adult female OVX rats was enhanced by NMDA in $\mathrm{E}_{2}$ - but not vehicle-treated animals [13]. Similarly, MK-801, a competitive NMDAR antagonist, affected pulsatile LH release only in $\mathrm{E}_{2}$ - but not vehicle-treated sheep [62]. The site of convergence of estrogens and glutamate is still unknown, but in the case of $\mathrm{GnRH}$ release, it is likely to occur via inputs to the $\mathrm{GnRH}$ system rather than in GnRH neurons themselves [63]. Importantly, estrogen receptor- $\alpha(\mathrm{ER} \alpha)$ and NMDARs are co-expressed in cells in regions of the hypothalamus and preoptic area that regulate GnRH neurons [29], suggesting an anatomical site at which endogenous glutamate and estrogens can interact upon the same target cells to enhance the sensitivity of the GnRH system. Alternatively, or in addition, we cannot exclude the possibility that an enhanced pituitary responsiveness to $\mathrm{GnRH}$ in the presence of $E_{2}$ may amplify effects of ifenprodil on LH pulsatility. Taken together, this evidence suggests that NMDAR antagonists may require modulation by estrogen in order to affect pulsatile LH release, a conclusion that is consistent with the results of this study showing stimulatory effects of ifenprodil only in $\mathrm{E}_{2}$-treated rats.

\section{Effects of Ifenprodil on LH Release Occur}

Independently of Effects on GnRH Gene Expression

Overall, robust effects of ifenprodil on GnRH mRNA levels, an index of GnRH gene expression, were not detected. Only the middle-aged, OVX rats that were cholesterol (but not $\mathrm{E}_{2}$ ) treated had decreased GnRH mRNA levels following ifenprodil compared to its vehicle control. This change, while significant, was not large in magnitude, and it is notable that this same group of rats did not respond to ifenprodil with a significant change in pulsatile $\mathrm{LH}$ release. This finding, together with our observations that ifenprodil significantly increases pulsatile $\mathrm{LH}$ release in the $\mathrm{E}_{2}$-treated young and middle-aged rats, suggests an uncoupling of $\mathrm{GnRH}$ biosynthesis and $\mathrm{GnRH}$ release. Therefore, the majority of the effects of ifenprodil probably occur on the secretory pool of GnRH vesicles that stimulate LH pulses from the pituitary gland, without causing changes in GnRH biosynthesis, at least at the time points measured. There are several alternative or complementary explanations. It is possible that changes in GnRH mRNA may occur more rapidly (e.g., within 15 min to $1 \mathrm{~h}$ ), similar to what has been reported for effects of $N$-methyl-D,L-aspartate $[42,64]$, whereas in the current study, rats were euthanized $4 \mathrm{~h}$ after ifenprodil injection. Alternatively, GnRH mRNA may replenish pools of the $\mathrm{GnRH}$ peptides over a longer time course. Future 
studies evaluating the time course of effects of ifenprodil on GnRH gene expression will enable us to detect whether this is a target for effects of NR2b antagonism. The concept that NMDAR agonists and antagonists may exert differential effects on GnRH cell bodies (as manifested by changes in gene expression) and on GnRH nerve terminals (as manifested by $\mathrm{GnRH}$ release) is one that we have posited previously [65] and is consistent with reports that not only do GnRH cell bodies co-express NMDAR subunits [2], but that $\mathrm{GnRH}$ nerve terminals express NMDAR subunits $[55,66,67]$ and may be a direct site of regulation by glutamate, independent of activity on GnRH perikarya.

Previous studies have shown that administration of NMDAR agonists stimulates GnRH gene expression, and that this effect is dependent upon reproductive status, age, sex, hormonal status, and the time points observed following administration $[42,68,69]$. There is much less information as to the effect of NMDAR antagonists on GnRH gene expression. Seong et al. [70] reported that administration of the NMDAR antagonist MK-801 to OVX, estrogen- and progesterone-treated adult female rats caused a decrease in GnRH gene expression in hypothalamic fragments. Ottem et al. [69] found that while estrogen induced an increase in $\mathrm{GnRH}$ gene expression in lateral and medial POA, MK-801 was not effective in inhibiting this increase. Our results showed no effect of ifenprodil on $\mathrm{GnRH}$ gene expression in $\mathrm{E}_{2}$-treated OVX rats of either age, and a small but significant decrease in GnRH mRNA levels only in middle-aged OVX rats, in the absence of $E_{2}$. These data reinforce previous work showing that the sensitivity of this system, depending upon time of day, estrous cycle status, and/or hormonal environments, together determine GnRH gene expression.

\section{Conclusions}

This study provides further evidence that the subunit composition of the NMDAR, and specifically the NR2b subunit, contributes to the regulation of $\mathrm{GnRH} / \mathrm{LH}$ release in the female hypothalamus. Blockade of NMDARNR2b in the presence of $E_{2}$ has a stimulatory effect on GnRH neurons, resulting in increased pulsatile LH output. Although pulsatile release of LH was similarly affected by ifenprodil in the two age groups, GnRH mRNA expression was selectively decreased only in one group, the cholesterol-treated middle-aged rats. These results suggest a dissociation of effects of glutamate, acting through NMDA receptors containing the NR2b subunit, on pulsatile GnRH release and GnRH gene expression.

\section{Acknowledgments}

This work was supported by the Glenn/American Federation for Aging Research (AFAR) scholarship for research in the biology of aging to J.A.M., and NIH PO1 AG16765 and RO1 AG028051 to A.C.G. We wish to thank Dr. Wendy Lou for statistical analysis of pulsatile LH release. Thanks also to Brittany Makos for excellent technical assistance in all areas of this study. We are grateful to Dr. A.F. Parlow of the National Hormone and Pituitary Program at NIDDK for providing LH assay reagents.

\section{References}

1 Mahesh VB, Brann DW: Regulatory role of excitatory amino acids in reproduction. Endocrine 2005;28:271-280.

2 Miller BH, Gore AC: N-Methyl-D-aspartate receptor subunit expression in GnRH neurons changes during reproductive senescence in the female rat. Endocrinology 2002; 143:3568-3574.

\3 Gore AC, Wu TJ, Rosenberg JJ, Roberts JL: Gonadotropin-releasing hormone and NMDA receptor gene expression and colocalization change during puberty in female rats. J Neurosci 1996;16:5281-5289.

4 Bailey JD, Centers A, Jennes L: Expression of AMPA receptor subunits (GluR1-GluR4) in gonadotrophin-releasing hormone neurones of young and middle-aged persistently oestrous rats during the steroid-induced luteinising hormone surge. J Neuroendocrinol 2006;18:1-12.
Ping L, Mahesh VB, Brann DW: Effect of NMDA and non-NMDA receptor antagonists on pulsatile luteinizing hormone secretion in the adult male rat. Neuroendocrinology 1995;61:226-234.

6 Ondo JG, Pass KA, Baldwin R: The effects of neurally active amino acids on pituitary gonadotropin secretion. Neuroendocrinology 1976;21:79-87.

$\checkmark 7$ Donoso AO, Lopez FJ, Negro-Vilar A: Glutamate receptors of the non- $N$-methyl-D-aspartic acid type mediate the increase in luteinizing hormone-releasing hormone release by excitatory amino acids in vitro. Endocrinology 1990;126:414-420.

-8 Brann DW, Mahesh VB: Excitatory amino acid regulation of gonadotropin secretion: modulation by steroid hormones. J Steroid Biochem Mol Biol 1992;41:847-850.
Bourguignon JP, Gerard A, Mathieu J, Simons J, Franchimont P: Pulsatile release of gonadotropin-releasing hormone from hypothalamic explants is restrained by blockade of $\mathrm{N}$-methyl-D,L-aspartate receptors. Endocrinology 1989;125:1090-1096.

10 Arslan M, Pohl CR, Plant TM: D,L-2-Amino5-phosphonopentanoic acid, a specific $N$ methyl-D-aspartic acid receptor antagonist, suppresses pulsatile $\mathrm{LH}$ release in the rat. Neuroendocrinology 1988;47:465-468.

11 Ping L, Mahesh VB, Brann DW: A physiological role for $N$-methyl-D-aspartic acid and non- $N$-methyl-D-aspartic acid receptors in pulsatile gonadotropin secretion in the adult female rat. Endocrinology 1994;135:113118 . 
$>12$ Bonavera JJ, Swerdloff RS, Sinha Hakim AP, 26 Gore AC, Yeung G, Morrison JH, Oung T: Lue $\mathrm{YH}$, Wang C: Aging results in attenuated gonadotropin releasing hormone-luteinizing hormone axis responsiveness to glutamate receptor agonist $N$-methyl-D-aspartate. J Neuroendocrinol 1998;10:93-99.

13 Arias P, Jarry H, Leonhardt S, Moguilevsky JA, Wuttke W: Estradiol modulates the LH release response to $N$-methyl-D-aspartate in adult female rats: studies on hypothalamic luteinizing hormone-releasing hormone and neurotransmitter release. Neuroendocrinology 1993;57:710-715.

14 Arias P, Carbone S, Szwarcfarb B, Feleder C, Rodriguez M, Scacchi P, Moguilevsky JA: Effects of aging on N-methyl-D-aspartate-induced GnRH and LH release in female rats. Brain Res 1996;740:234-238.

15 Gallo RV: Pulsatile LH release during the ovulatory LH surge on proestrus in the rat. Biol Reprod 1981;24:100-104.

16 Steiner RA, Bremner WJ, Clifton DK: Regulation of luteinizing hormone pulse frequency and amplitude by testosterone in the adult male rat. Endocrinology 1982;111:20552061.

-17 Belchetz PE, Plant TM, Nakai Y, Keogh EJ, Knobil E: Hypophysial responses to continuous and intermittent delivery of hypothalamic gonadotropin-releasing hormone. Science 1978;202:631-633.

18 Mandl AM: Cyclical changes in the vaginal smears of senile nulliparous and multiparous rats. J Endocrinol 1961;22:257-268.

$\checkmark 19$ Huang HH, Meites J: Reproductive capacity of aging female rats. Neuroendocrinology 1975; 17:289-295.

-20 Huang HH, Steger RW, Bruni JF, Meites J: Patterns of sex steroid and gonadotropin secretion in aging female rats. Endocrinology 1978; 103:1855-1859.

- 21 Estes KS, Simpkins JW, Chen CL: Alteration in pulsatile release of LH in aging female rats. Proc Soc Exp Biol Med 1980;163:384387.

-22 Karpas AE, Bremner WJ, Clifton DK, Steiner RA, Dorsa DM: Diminished luteinizing hormone pulse frequency and amplitude with aging in the male rat. Endocrinology 1983;112:788-792.

23 Scarbrough K, Wise PM: Age-related changes in pulsatile luteinizing hormone release precede the transition to estrous acyclicity and depend upon estrous cycle history. Endocrinology 1990;126:884-890.

24 Maffucci JA, Gore AC: Age-related changes in hormones and their receptors in animal models of female reproductive senescence; in Conn PM (ed): Handbook of Models for the Study of Human Aging. New York, Academic Press, 2006.

25 Funabashi T, Kimura F: The number of luteinizing hormone-releasing hormone immunoreactive neurons is significantly decreased in the forebrain of old-aged female rats. Neurosci Lett 1995;189:85-88.
Neuroendocrine aging in the female rat: the changing relationship of hypothalamic gonadotropin-releasing hormone neurons and $\mathrm{N}$-methyl-D-aspartate receptors. Endocrinology 2000;141:4757-4767.

27 Rubin BS, King JC: The number and distribution of detectable luteinizing hormone (LH)-releasing hormone cell bodies changes in association with the preovulatory LH surge in the brains of young but not middleaged female rats. Endocrinology 1994;134: 467-474.

28 Neal-Perry GS, Zeevalk GD, Santoro NF, Etgen AM: Attenuation of preoptic area glutamate release correlates with reduced luteinizing hormone secretion in middle-aged female rats. Endocrinology 2005; 146:43314339.

29 Chakraborty TR, Ng L, Gore AC: Colocalization and hormone regulation of estrogen receptor $\alpha$ and $N$-methyl-D-aspartate receptor in the hypothalamus of female rats. En-

30 Chakraborty TR, Hof PR, Ng L, Gore AC: Stereologic analysis of estrogen receptor $\alpha$ expression in rat hypothalamus and its regulation by aging and estrogen. J Comp Neurol 2003;466:409-421.

31 Gore AC, Oung T, Woller MJ: Age-related changes in hypothalamic gonadotropin-releasing hormone and $N$-methyl-D-aspartate receptor gene expression, and their regulation by oestrogen, in the female rat. J Neuroendocrinol 2002;14:300-309.

32 Gore AC: Gonadotropin-releasing hormone neurons, NMDA receptors, and their regulation by steroid hormones across the reproductive life cycle. Brain Res Brain Res Rev 2001;37:235-248.

33 Adams MM, Flagg RA, Gore AC: Perinatal changes in hypothalamic $N$-methyl-D-aspartate receptors and their relationship to gonadotropin-releasing hormone neurons. Endocrinology 1999;140:2288-2296.

34 Nathan BM, Hodges CA, Supelak PJ, Burrage LC, Nadeau JH, Palmert MR: A quantitative trait locus on chromosome 6 regulates the onset of puberty in mice. Endocrinology 2006;147:5132-5138.

35 National Research Council: Guide for the Care and Use of Laboratory Animals. Washington, National Academies Press, 1996.

36 Adams MM, Oung T, Morrison JH, Gore AC: Length of postovariectomy interval and age, but not estrogen replacement, regulate $N$ methyl-D-aspartate receptor mRNA levels in the hippocampus of female rats. Exp Neurol 2001;170:345-356.

37 Duvauchelle CL, Sapoznik T, Kornetsky C: The synergistic effects of combining cocaine and heroin ('speedball') using a progressiveratio schedule of drug reinforcement. Pharmacol Biochem Behav 1998;61:297-302. docrinology 2003;144:299-305.
38 Narita M, Soma M, Mizoguchi H, Tseng LF, Suzuki T: Implications of the NR2B subunitcontaining NMDA receptor localized in mouse limbic forebrain in ethanol dependence. Eur J Pharmacol 2000;401:191-195.

-39 Rodrigues SM, Schafe GE, LeDoux JE: Intraamygdala blockade of the NR2B subunit of the NMDA receptor disrupts the acquisition but not the expression of fear conditioning. J Neurosci 2001;21:6889-6896.

40 Jakubowski M, Roberts JL: Multiplex solution hybridization-ribonuclease protection assay for quantitation of different ribonucleic acid transcripts from snap-frozen neuroendocrine tissues of individual animals. J Neuroendocrinol 1992;4:79-89.

41 Medhurst AD, Harrison DC, Read SJ, Campbell CA, Robbins MJ, Pangalos MN: The use of TaqMan RT-PCR assays for semiquantitative analysis of gene expression in CNS tissues and disease models. J Neurosci Meth 2000;98:9-20.

42 Gore AC, Roberts JL: Regulation of gonadotropin-releasing hormone gene expression by the excitatory amino acids kainic acid and $N$-methyl-D,L-aspartate in the male rat. Endocrinology 1994;134:2026-2031.

43 Pfaffl MW: A new mathematical model for relative quantification in real-time RT-PCR. Nucleic Acids Res 2001;29:e45.

44 Veldhuis JD, Johnson ML: Cluster analysis: a simple, versatile, and robust algorithm for endocrine pulse detection. Am J Physiol 1986;250:E486-E493.

45 Luderer U, Strobl FJ, Levine JE, Schwartz NB: Differential gonadotropin responses to $\mathrm{N}$-methyl-D,L-aspartate in metestrous, proestrous, and ovariectomized rats. Biol Reprod 1993;48:857-866.

46 Claypool LE, Kasuya E, Saitoh Y, Marzban F, Terasawa E: N-Methyl-D,L-aspartate induces the release of luteinizing hormone-releasing hormone in the prepubertal and pubertal female rhesus monkey as measured by in vivo push-pull perfusion in the stalk-median eminence. Endocrinology 2000;141:219-228.

-47 Williams K: Ifenprodil discriminates subtypes of the $N$-methyl-D-aspartate receptor: selectivity and mechanisms at recombinant heteromeric receptors. Mol Pharmacol 1993; 44:851-859.

48 Williams K: Ifenprodil, a novel NMDA receptor antagonist: site and mechanism of action. Curr Drug Targets 2001;2:285-298.

49 Benavides J, Peny B, Allen J, Scatton B: Pharmacological characterization of in vivo $\left[{ }^{3} \mathrm{H}\right]$ ifenprodil binding sites in the mouse brain. J Pharmacol Exp Ther 1992;260:896901.

50 Grimwood S, Richards P, Murray F, Harrison $\mathrm{N}$, Wingrove $\mathrm{PB}$, Hutson $\mathrm{PH}$ : Characterisation of $\mathrm{N}$-methyl-D-aspartate receptor-specific $\left[{ }^{3} \mathrm{H}\right]$ ifenprodil binding to recombinant human NR1a/NR2B receptors compared with native receptors in rodent brain membranes. J Neurochem 2000;75: $2455-2463$. 
-51 Schoepfer R, Monyer H, Sommer B, Wisden W, Sprengel R, Kuner T, Lomeli H, Herb A, Kohler M, Burnashev N, et al: Molecular biology of glutamate receptors. Prog Neurobiol 1994;42:353-357.

52 Eyigor O, Jennes L: Expression of glutamate receptor subunit mRNAs in gonadotropinreleasing hormone neurons during the sexual maturation of the female rat. Neuroendocrinology 1997;66:122-129.

-53 Meeker RB, Greenwood RS, Hayward JN: Glutamate receptors in the rat hypothalamus and pituitary. Endocrinology 1994;134: 621-629.

-54 Herman JP, Eyigor O, Ziegler DR, Jennes L: Expression of ionotropic glutamate receptor subunit mRNAs in the hypothalamic paraventricular nucleus of the rat. J Comp Neurol 2000;422:352-362.

-55 Kawakami SI, Hirunagi K, Ichikawa M, Tsukamura H, Maeda KI: Evidence for terminal regulation of $\mathrm{GnRH}$ release by excitatory amino acids in the median eminence in female rats: a dual immunoelectron microscopic study. Endocrinology 1998;139:14581461.

56 Vicini S, Wang JF, Li JH, Zhu WJ, Wang YH, Luo JH, Wolfe BB, Grayson DR: Functional and pharmacological differences between recombinant $N$-methyl-D-aspartate receptors. J Neurophysiol 1998;79:555-566.

57 Hatton CJ, Paoletti P: Modulation of triheteromeric NMDA receptors by $N$-terminal domain ligands. Neuron 2005;46:261-274.
8 Leranth C, MacLusky NJ, Sakamoto H, Shanabrough M, Naftolin F: Glutamic acid decarboxylase-containing axons synapse on LHRH neurons in the rat medial preoptic area. Neuroendocrinology 1985;40:536539.

59 Petersen SL, McCrone S, Coy D, Adelman JP, Mahan LC: GABAA receptor subunit mRNAs in cells of the preoptic area: colocalization with LHRH mRNA using dual-label in situ hybridization histochemistry. Endocrinology J 1993;1:29-34.

60 Ottem EN, Godwin JG, Krishnan S, Petersen SL: Dual-phenotype GABA/glutamate neurons in adult preoptic area: sexual dimorphism and function. J Neurosci 2004;24: 8097-8105.

61 Grove-Strawser D, Jimenez-Linan M, Rubin BS: Middle-aged female rats lack the dynamic changes in GAD(67) mRNA levels observed in young females on the day of a luteinising hormone surge. J Neuroendocrinol 2007;19:708-716.

62 Jiang H, Haglof SA, Malven PV: Transient effects of MK-801 administration on secretion of luteinizing hormone and prolactin in ovariectomized and estradiol-treated sheep. Life Sci 1997;60:1447-1456.

63 Wintermantel TM, Campbell RE, Porteous R, Bock D, Grone HJ, Todman MG, Korach KS, Greiner E, Perez CA, Schutz G, Herbison AE: Definition of estrogen receptor pathway critical for estrogen positive feedback to gonadotropin-releasing hormone neurons and fertility. Neuron 2006;52:271-280.

-64 Petersen SL, McCrone S, Keller M, Gardner E: Rapid increase in LHRH mRNA levels following NMDA. Endocrinology 1991;129: 1679-1681.
65 Yin W, Gore AC: Neuroendocrine control of reproductive aging: roles of $\mathrm{GnRH}$ neurons. Reproduction 2006;131:403-414.

66 Kawakami S, Ichikawa M, Murahashi K, Hirunagi K, Tsukamura H, Maeda K: Excitatory amino acids act on the median eminence nerve terminals to induce gonadotropin-releasing hormone release in female rats. Gen Comp Endocrinol 1998;112:372-382.

67 Yin W, Mendenhall JM, Bratton SB, Oung T, Janssen WG, Morrison JH, Gore AC: Novel localization of NMDA receptors within neuroendocrine gonadotropin-releasing hormone terminals. Exp Biol Med (Maywood) 2007;232:662-673.

68 Liaw JJ, Barraclough CA: N-Methyl-D,L-aspartic acid differentially affects LH release and LHRH mRNA levels in estrogen-treated ovariectomized control and androgen-sterilized rats. Brain Res Mol Brain Res 1993;17: $112-118$.

69 Ottem EN, Godwin JG, Petersen SL: Glutamatergic signaling through the $N$-methyl-Daspartate receptor directly activates medial subpopulations of luteinizing hormone-releasing hormone (LHRH) neurons, but does not appear to mediate the effects of estradiol on LHRH gene expression. Endocrinology 2002;143:4837-4845.

70 Seong JY, Lee YK, Lee CC, Kim K: NMDA receptor antagonist decreases the progesterone-induced increase in GnRH gene expression in the rat hypothalamus. Neuroendocrinology 1993;58:234-239. 